\title{
A OPINIÃO PÚBLICA SOBRE CRIMES CORPORATIVOS: O QUE PENSAM OS ESTUDANTES DE CURSOS DE GRADUAÇÃO DA ÁREA DE NEGÓCIOS
}

\author{
PUBLIC OPINION OF CORPORATE CRIME: \\ THE THOUGHTS OF UNDERGRADUATE \\ BUSINESSAND ADMINISTRATION STUDENTS
}

Recebido em: 07/10/2015 A Aprovado em: 21/12/2015

Avaliado pelo sistema double blind review

Editora Científica: Cláudia de Salles Stadtlober

DOI: $10.13058 /$ raep.2016.v17n1.225

\author{
SABRINA RAFAELA PEREIRA BORGES sabrinarpb@yahoo.com.br \\ CINTIA RODRIGUES DE OLIVEIRA MEDEIROS \\ NADIA GIARETTA BIASE \\ VALDIR MACHADO VALADÃO JÚNIOR \\ UNIVERSIDADE FEDERAL DE UBERLÂNDIA
}

\begin{abstract}
RESUMO
Esta pesquisa aborda a opinião pública sobre os crimes e ilegalidades corporativas. É possível que atuais estudantes da área de negócios, no exercício futuro da função de gestores, enfrentem situações que demandem decisões, muitas vezes, com consequências danosas, o que exige uma postura ética e reflexiva acerca das condutas a serem tomadas, bem como de suas consequências. O objetivo desta pesquisa é caracterizar a opinião dos estudantes de graduação na área de negócios a respeito dos crimes corporativos, buscando compreender o que impulsiona as atuais opiniões desse público sobre questões importantes associadas ao tema. Esta é uma pesquisa de natureza quantitativa, realizada por meio de um questionário estruturado. Os resultados apontam que, em geral, há um nível médio de conhecimento dos estudantes sobre esta temática e, em relação à gravidade dos crimes corporativos, os estudantes consideram o "uso de mão de obra infantil e trabalho escravo" como aquele de maior gravidade em relação aos outros crimes e ilegalidades corporativas. Ainda, evidenciou-se que os pesquisados consideram os crimes de rua mais graves do que os crimes corporativos.

Palavras-chave: estudantes; crime corporativo; ilegalidade corporativa; opinião pública.
\end{abstract}

\footnotetext{
ABSTRACT

This research addresses public opinion on corporate crimes and illegalities. Current business and administration students may well face, once employed in management positions, situations that require decisions, often with damaging consequences. This requires a thoughtful and ethical approach regarding the actions to be taken and their consequences. The objective of this research is to characterize the views of undergraduate business and administration students on corporate crime, with the aim of understanding what drives this audience's current views of important issues associated to the theme. This is a quantitative study undertaken through a structured questionnaire. The results show that, in general, the students have an average level of knowledge of the subject and, as regards severity, they consider "the use of child and slave labor" as the most serious among corporate crimes and illegalities. Furthermore, it became clear that respondents consider street crime as more serious than corporate crime.

Keywords: students; corporate crime; corporate illegality; public opinion.
} 


\section{INTRODUÇÃO}

Condutas ilegais e criminosas trazem severas consequências para seus diversos stakeholders, sendo esses atos, muitas vezes, encobertos e esquecidos pela sociedade. Um dos aspectos que deve ser considerado é a dificuldade em distinguir o que são atos criminosos e comportamentos ilícitos, e ainda, se esses são de responsabilidade da empresa ou dos indivíduos. O lado sombrio é discutido por Morgan (1996) como um desafio para aqueles que estudam as organizações, pois é nele que emergem crimes, falhas, acidentes, tragédias ou fatalidades que ocorrem dentro da lógica operacional da organização que, por sua vez, é determinada por regulamentos, normas e procedimentos previamente estabelecidos, de forma a alcançar os objetivos corporativos de lucro, poder e influência.

A criminalidade corporativa é um dos temas importantes para discussão no campo dos estudos organizacionais, pois, a partir de 1970, o número de escândalos corporativos vem crescendo e ainda é complexa sua compreensão no que se refere às suas características (tipos e estatísticas), suas causas e consequências. Além do mais, de modo geral, nos estudos na área de administração, apenas é apontado o bright side ${ }^{\mathrm{r}}$ das organizações e pouco se discutem os aspectos negativos, os quais parecem não fazer parte do contexto organizacional (MORGAN, I996; GRIFFIN, 20IO).

Medeiros e Alcadipani (20I3) apontam as causas do comportamento criminoso e ilícito em organizações, bem como as definições do que consiste um crime corporativo e uma ilegalidade corporativa, apresentando dados que fundamentam as consequências desses atos. Nesse contexto, torna-se relevante conhecer a opinião pública sobre o controle da ilegalidade no mundo dos negócios. As pesquisas sobre a opinião pública podem identificar quais delitos são considerados mais graves e quais características moderam as percepções da sociedade sobre os crimes e ilegalidades nos contextos organizacionais.

A educação de executivos e administradores tem sido questionada pela sua formação focada na instrumentalidade, uma vez que as escolas de

1 Lado que brilha no sentido de transparente, visível. 
Administração e de gestão não estão formando profissionais questionadores e que visam uma transformação social, mas, sim, profissionais que seguem os modelos construídos em outros países, principalmente, nos Estados Unidos (MOTTA, I983; GREY; KNIGHTS; WILMOTT, I996; NICOLINI, 2003; AKTOUF, 2005; PATON; CHIA; BURT, 20I4).

Diante desse cenário, diversas questões vêm à tona: Como os estudantes da área de gestão compreendem os crimes corporativos? Os crimes de ruas são vistos como mais graves do que os crimes corporativos por esses estudantes? Qual é o papel a ser desempenhado pelo profissional formado na área de negócios quanto ao combate aos crimes corporativos? De forma sintética, este estudo está voltado para o entendimento da seguinte questão: Qual é a opinião dos estudantes da área de negócios a respeito dos crimes e ilegalidades corporativas?

Para responder a essa questão, estabelecemos que o objetivo geral desta pesquisa é o de caracterizar a opinião dos estudantes de graduação na área de negócios, de instituições públicas e privadas, delimitadas na cidade de Uberlândia/MG, a respeito dos crimes e ilegalidades corporativas, buscando a compreensão do que impulsiona as atuais percepções desse público sobre questões associadas ao tema. Mais especificamente, os propósitos desta pesquisa são: identificar o nível de conhecimento dos pesquisados sobre o tema em questão; identificar a percepção dos pesquisados quanto à gravidade dos crimes corporativos; conhecer a opinião dos pesquisados sobre o combate dos crimes corporativos; e estabelecer relações entre as respostas encontradas e os perfis dos pesquisados.

Nesse contexto, os jovens gestores em formação devem desempenhar um papel importante para evitar os crimes corporativos, e, portanto, devem assumir uma postura crítica diante desses acontecimentos, uma vez que devem lidar com decisões envolvendo essas práticas nas organizações. Desse modo, este estudo é importante por mostrar a relevância da discussão dessa temática no componente curricular dos estudantes, especialmente, na área de gestão, nas diversas instituições de ensino. Isso porque a problematização apresentada anteriormente aponta para a necessidade de os futuros gestores serem capazes de atribuir sentido, compreender e 
gerenciar sistemas contraditórios e ambíguos, constituídos por uma ampla variedade de elementos que se inter-relacionam: expectativas, sentimentos, discursos, identidades, demandas, valores, interesses e práticas (BORGEs; MEDEIROS; CASADO, 2OII).

Quanto aos procedimentos metodológicos adotados, esta é uma pesquisa de natureza quantitativa que se utiliza de um questionário estruturado para coletar a opinião dos estudantes selecionados pelo critério de acessibilidade. As hipóteses da pesquisa foram testadas com base em inferência estatística, aplicando-se teste de Qui-Quadrado de independência com um nível de significância de $5 \%$. No processo de tabulação dos dados, 26 respostas foram descartadas por problemas de preenchimento ou por não se enquadrarem no objeto de estudo da pesquisa. Desse modo, das 470 respostas obtidas, 444 foram validadas.

Este artigo está estruturado em cinco seções: a primeira é esta introdução, em que são apresentados o contexto da pesquisa, a problematização, a justificativa, a importância e seus objetivos. Na segunda, apresenta-se a literatura pesquisada a respeito da opinião pública sobre Crimes Corporativos e os aspectos gerais da formação de gestores. Na terceira seção, descrevem-se os aspectos metodológicos do estudo; a penúltima apresenta os resultados e sua discussão à luz do referencial teórico. Por fim, as considerações finais do estudo encerram o artigo. 


\section{A OPINIÃO PÚBLICA EM RELAÇÃO AOS CRIMES CORPORATIVOS}

A opinião pública desempenha papel fundamental no debate sobre a culpabilidade das corporações, visto sua influência no controle das ilegalidades no mundo dos negócios (ALMOND, 2009; PAYNE, 2012). Conforme Szwajkowski (1985), a população em geral considera as ofensas corporativas como sérias apenas quando suas consequências são físicas, substanciais e, relativamente, imediatas. Todavia, conforme Sutherland (1940, p. 5) afirma, "White collar crime é um crime real", e mesmo que não seja denominado de crime, ordinariamente, isso não o torna menor. A opinião pública desempenha, ainda, papel relevante na regulação e controle dos crimes corporativos. Tanto é importante que, conforme Schrager e Short (1978), a ambiguidade da opinião pública diante do comportamento corporativo ilegal faz com que a lei também seja ambígua.

Sutherland (194I) sugere que, quando se trata de crimes corporativos, como os diretores e executivos da corporação são homens de respeitabilidade, existe um interesse em preservar o prestígio desses e da própria corporação. E é nesse ponto que o autor argumenta contra o tratamento homogêneo para todos os tipos de crime, principalmente, no que diz respeito à designação de crime ser atribuída somente se houver a condenação, haja vista que crimes cometidos por pessoas de alto status econômico, denominados de "crime in the suites" têm tratamento diferente em relação aos procedimentos administrativos utilizados quando os perpetradores pertencem a uma classe socioeconômica mais baixa, no caso dos crimes de rua ou street crimes, termo utilizado para se referir a qualquer tipo de ofensa cometida em locais públicos.

Nessa direção, Sutherland (1940) se opõe à generalização das teorias tradicionais para explicar tanto os crimes corporativos quanto os crimes de rua. Isso porque as diferenças entre esses dois tipos e as suas implicações, na aplicação de leis, de posições sociais dos criminosos, entre outras, são significativas para que tenham o mesmo tratamento. Por exemplo, aqueles que praticam o crime corporativo têm posições privilegiadas na sociedade, influenciando, até mesmo, na elaboração e interpretação das leis criminais, diferentemente, daqueles que cometem os crimes de rua. 
No caso dos crimes corporativos, tanto o público em geral, quanto as próprias vítimas não têm mostrado interesse tanto quanto em relação aos crimes de rua, o que pode influenciar a forma como os infratores são condenados nos tribunais. Assim, de acordo com Rebovich e Kane (2002), o movimento para combater eficazmente a prática desses crimes tem sido lenta por causa da falta de informações para o público em geral sobre a ocorrência e a ameaça de tais ações.

Usando uma amostra probabilística, Unnever, Benson e Cullen (2008) investigaram se a população dos Estados Unidos queria aprovar regulamentos mais rigorosos do mercado de ações e defender sanções penais mais punitivas para os executivos corporativos que ocultassem a verdadeira condição financeira da empresa. No entanto, pesquisas recentes indicam que a população não compreende que os crimes corporativos sejam tão problemáticos quanto os crimes de rua. Sutherland (1940), que primeiro escreveu sobre o crime do colarinho branco, em teoria criminológica, na primeira metade do século $\mathrm{xx}$, ficou desapontado com a falta do interesse público na nova forma de crime apontada naquela época. Rebovich e Kane (2002) também mostram outras pesquisas que indicam um crescente desdém público para os crimes corporativos.

Uma questão muito importante se levanta: como investigar esse lado sombrio das organizações se as pessoas não têm a devida compreensão sobre esse tema? Assim, conforme Wood Jr. e Caldas (2007), as pessoas, no espaço organizacional, tendem a evitar serem testemunhas de ações injustas e más condutas organizacionais, muitas vezes, sendo omissas em relação a tais atos.

Rebovich e Kane (2002) apresentam resultados de uma pesquisa realizada com I.I69 famílias nos Estados Unidos que desafiam algumas dessas crenças de apatia pública para com o crime de colarinho branco. Os resultados mostram que muitos pesquisados acreditam que a fraude corporativa pode ser tão grave ou mais grave do que certos tipos de crimes de rua. O nível de condenação moral do crime corporativo provou ser mais elevado do que o previsto, particularmente quando os crimes estavam associados a casos de corrupção. Surpreendentemente, as vítimas dos crimes não é um fator que influencia as atitudes de punição para os crimes corporativos, exceto nos 
casos em que os crimes tinham o potencial de impacto de longo alcance financeiro. Os autores concluíram que a cobertura da mídia sobre o crime corporativo pode afetar a percepção do público sobre o entendimento e a gravidade dos crimes corporativos. Como complemento, Medeiros e Alcadipani (2013) destacam que muitos casos "passam despercebidos" pela opinião pública no Brasil devido à prática da parcialidade dos meios de comunicação nacionais, que têm como clientes corporações que gastam montantes elevados com publicidade.

Oliveira, Valadão Júnior e Miranda (20I3) mostram que, quando se tem escândalos na mídia envolvendo organizações em ações criminosas, essas acabam utilizando de seus discursos ideológicos para se defenderem, muitas vezes colocando a culpa de determinadas responsabilidades sobre terceiros. Desse modo, as Corporações preferem não assumir os custos advindos de seus comportamentos ilícitos, e esses custos sociais e ambientais acabam sendo deslocados para a sociedade. Dessa forma, enquanto os trabalhadores forem obrigados a se sujeitarem às péssimas condições de trabalho e os consumidores não reduzirem o seu consumo, o crime corporativo continuará existindo.

De acordo com Friedrichs (2010), a partir da década de 1960, houve um crescimento do interesse público sobre o tema decorrente de uma maior consciência da ilegalidade corporativa, da ansiedade dos consumidores e da política em geral. Além disso, pesquisas de opinião pública mostram que, na década de I970, o crime de colarinho branco atingiu maior significado na mente da população. A venda de comida contaminada que resulta em morte passou da colocação como crime mais grave de $26^{\circ}$ lugar, em I972, para $13^{\circ}$ lugar, em 1979 (SIMPSON, 2002).

Cullen, Bruce e Craig (I982) fizeram um estudo sobre as atitudes das pessoas em relação ao crime corporativo em particular. Os autores mostraram que as atitudes do público em relação à criminalidade corporativa tinham endurecido significativamente. O problema é que a maioria das pessoas somente dá a devida importância ao crime corporativo quando percebe alguma consequência drástica para sociedade em geral, justamente, pelo fato de a sociedade se preocupar muito com o foco do curto prazo. Nesse sentido, de acordo com Borges, Medeiros e Casado (20II), existe um novo 
desafio para que esses assuntos estejam mais presentes na formação de profissionais na área de negócios, como o curso de Administração, o que é algo complexo, haja vista a cultura brasileira de aversão às incertezas e os vários mitos existentes em torno da ética na gestão. Portanto, necessário se faz estimular os alunos a desenvolverem uma visão crítica e reflexiva de que administrar não envolve apenas planejar, coordenar, dirigir e controlar. É preciso repensar sobre a forma de ser fazer negócios, visto que leis e códigos de éticas não serão suficientes para a inibição de tais práticas se as pessoas e organizações não mudarem seus valores e cultura (ALCADIPANI, 20I4).

De acordo com Coleman (2005), assim como nos outros tipos de crimes, todas as pessoas que participaram de forma direta ou indireta deverão ser punidas. O problema é que, no crime corporativo, apenas um infrator, normalmente, é considerado culpado, e as outras pessoas e empresas envolvidas ficam impunes. Os crimes cometidos por indivíduos da classe baixa $^{2}$ são tratados com sanções penais, sob a forma de multas e prisão. Já os crimes da classe alta não resultam em uma ação criminal; isto é, ou resultam em ações indenizatórias em tribunais civis, ou são manipulados pelos inspetores, e por conselhos ou comissões administrativas, com sanções penais na forma de avisos, ordens para cessar e desistir, e, ocasionalmente, na perda de uma licença. O fato é que, nos crimes cometidos por indivíduos da classe alta, somente em casos extremos são aplicadas multas ou penas de prisão.

Os criminosos de colarinho branco são segregados administrativamente de outros criminosos, e, por isso, não são considerados como verdadeiros criminosos pelo público em geral. Essa diferença pode ser explicada pelo fato de a classe alta ter maior influência na moldagem do direito penal do que a classe baixa. A privilegiada posição dos criminosos de colarinho branco perante a lei resulta de uma ligeira medida das pressões de suborno a políticos. Em contraste com o poder dos criminosos de colarinho branco está a fraqueza de suas vítimas. Os consumidores, investidores e a sociedade

\footnotetext{
2 Neste trabalho, a denominação classe baixa e classe alta decorre da tradução literal das obras pesquisadas, entendendo referir-se à classe social de pessoas com renda baixa e renda alta, respectivamente.
} 
como um todo não possuem conhecimento e poder suficientes, e, assim, acabam se tornando as principais vítimas (COLEMAN, 2005).

Borges e Medeiros (2014) destacam que as grandes corporações, especialmente as multinacionais, tendem a apresentar maior quantidade de processos, não só relacionado a problemas com clientes, mas, também, com o meio ambiente e até fornecedores. Além disso, as pesquisas de opinião pública mostram que as empresas de grande porte tendem a ser vistas como mais criminosas pela sociedade (COLEMAN, 2005). No entanto, os crimes corporativos não são vistos pelo público como crimes de alta gravidade, o que discutimos em seguida.

\section{A FORMAÇÃO DE ADMINISTRADORES NO CONTEXTO CONTEMPORÂNEO}

Nesta seção, concentramo-nos na discussão sobre o ensino e a formação de profissionais de área de negócios, dando ênfase ao ensino em Administração. Desde que os escândalos corporativos ganharam maior evidência, no início da primeira década do século xxI, as escolas de negócios vêm recebendo críticas e questionamentos sobre a sua responsabilidade da formação de profissionais responsáveis pela gestão das organizações (WELSH; DEHLER, 2007; RUBIN; DIERDORFF, 2009). Em 2009, a Harvard Business Review promoveu um debate "How to fix Business Schools" com o propósito de discutir questões como: "Muitos críticos acusaram que os valores transmitidos em programas de MBA têm contribuído significativamente para os lapsos éticos e estratégicos que levaram à atual crise econômica. Isso é justo? E se assim for, o que precisa mudar? Como podem as escolas de negócios recuperar a confiança popular?” (HBR, 2009). Essa iniciativa aponta para os desafios da formação de gestores, o que também se reflete quando se discute o ensino em Administração, pois esses cursos se institucionalizaram como o caminho para a formação de gestores capazes de conduzir as organizações, prevalecendo à ideia de que a educação formal oferece resultados mais efetivos nesse campo (RUBIN; DIERDORFF, 2009).

Entre as críticas dirigidas à formação profissional de administradores e de executivos em geral, estão aquelas que se manifestam a favor de uma 
reflexão sobre a educação executiva e o papel das escolas de negócios na formação de gestores, bem como sobre o modo pelo qual esses fazem a gestão das empresas (BENNIS; O’TOOLE, 2005; GHOSHAL, 2005; MITROFF, 2004; GIOIA, 2002, entre outros). O fato é que, a despeito desses esforços em debater a educação executiva, pouco se tem discutido sobre a principal inquietação de Adler (2002) quanto a uma crise de confiança em relação às instituições envolvidas na formação de profissionais que tomam decisões no mundo de negócios, as quais impactam a vida na sociedade.

Aproximam-se da inquietação de Adler (2002) estudos que se debruçam para explorar as percepções de estudantes de administração sobre o ensino de responsabilidade social corporativa (FERREIRA; FERREIRA; FARIA 2OII; SILVA; CHAUVEL, 2OII; SANTOS; SILVA, 20I3, entre outros), para questionar a formação tecnicista em detrimento de uma visão humanista e social (GREY, 2004; AKTOUF, 2005; FONTENELLE, 2007, entre outros), para estimular reflexões sobre a formação do administrador (TEIXEIRA; SILVA; MAFRA, 20II; BARCELLOS; DELLAGNELO; SALIÉs, 20II, entre outros). Esses estudos apontam para a necessidade de mudanças nas propostas pedagógicas dos cursos de Administração, bem como nas relações entre universidade e sociedade, de modo a potencializar mudanças na formação de administradores que se distanciem da lógica puramente técnico-econômica e busquem formas alternativas para gerir as organizações. Isso, considerando que esses profissionais devam ser sujeitos críticos de práticas que vão de encontro aos anseios de uma sociedade, como no caso de crimes corporativos e outras ilegalidades.

\section{A OPINIÃO PÚBLICA QUANTO À GRAVIDADE E PUNIÇÃO DOS CRIMES CORPORATIVOS}

Para Frank et al. (1989), a literatura sobre as atitudes do público em relação à punição ou a gravidade do comportamento criminoso nas organizações foi amplamente negligenciada ao se concentrar, sistematicamente, sobre cinco temas: (I) a percepção pública da ilegalidade corporativa, ao invés de percepções de crimes de rua ou outras formas de ilegalidades sem ser o crime do colarinho branco; (2) as avaliações são condicionadas pelo grau 
de culpabilidade e prejuízos resultados da ação; (3) as circunstâncias em que os cidadãos irão apoiar o uso de sanções legais contra um executivo em oposição a uma entidade corporativa; (4) a disposição do público para apoiar criminosos em oposição à intervenção civil, em vários tipos de atividades empresariais ilegais; e (5) as atitudes dos executivos de negócios em relação à sanção legal corporativa comparadas com as atitudes daqueles que estão em poder do público em geral.

Warr (1989) sugere que gravidade é um conceito composto que reflete nocividade e ilicitude, e mostra que esses dois fatores podem ditar diferentes classificações de gravidade em relação ao mesmo crime. Além disso, a intenção ou não por parte do crime cometido também pode refletir na classificação colocada pela pessoa.

De acordo com Rosenmerkel (200I), os crimes corporativos tendem a receber classificações menos graves pelo público em relação a outros tipos de crimes. A maior parte desses crimes ocorre em contextos e envolvem ações e resultados que são significativamente retirados do cotidiano e consciência do público em geral. Desse modo, o público tende a confiar no conceito de nocividade percebido ao considerar a gravidade dos crimes corporativos, ao invés de considerar as percepções de ilicitude, que são mais comumente usadas em relação às formas tradicionais de 'crimes de rua'. Essa tendência talvez reflita a ambiguidade moral atribuída aos crimes corporativos.

No entanto, a crescente atenção que o crime de colarinho branco tem recebido nos últimos anos levanta a possibilidade de mudanças nas percepções do público de tais violações. Ao replicar a pesquisa de Rossi et al. (1972) sobre a gravidade de 140 crimes, Cullen, Bruce e Craig (1982) apresenta dados que indicam que o crime corporativo aumentou em gravidade mais do que qualquer outra categoria de ofensa, no entanto, ainda é visto como menos grave do que a maioria das outras formas de ilegalidades.

Por outro lado, para Rebovich e Kane (2002), a crença de que o público tenha uma atitude neutra em relação a crime corporativo é, possivelmente, mais um mito do que realidade. Embora tenha havido alguns estudos de percepção da seriedade do público, aqueles realizados mostraram que o público manifesta um pouco mais de preocupação do que se acreditava 
anteriormente, sobretudo, nos casos em que o dano físico ou lesão é o resultado final. Após uma revisão de estudos internacionais sobre percepção pública de crime de colarinho branco, inclusive os estudos de Rossi, Cullen, e Wolfgang (2012), Rebovich e Kane (2002) notaram que o público percebe muitas formas de crime corporativo como mais grave, e que merecem punição mais severa do que a maioria das formas de crime comum.

Como complemento, os estudos de Hans e Ermann (1989) mostram que as infrações são significativamente classificadas como mais negligentes e sérias quando o réu é um órgão social do que quando é individual. Além disso, o dano percebido por uma pessoa depende de vários fatores: a) ligação entre o crime e o que se percebe; b) um contexto compartilhado; c) visibilidade do dano; ou d) consequência das ações percebidas (TVERSKY; KAHNEMAN, 1974).

A gravidade percebida pelo público em geral sobre o crime mantevese elevada na década de 1980. Uma pesquisa feita pelo Departamento de Justiça dos Estados Unidos, em 1984, mostrou que o crime ambiental foi considerado mais grave (ficou em sétimo lugar, atrás do assassinato, mas à frente do contrabando de heroína). Conforme a pesquisa, $84 \%$ dos respondentes percebiam os danos ambientais como um crime grave, e três, de cada quatro respondentes acreditavam que os executivos deveriam ser responsáveis por essas infrações. Ainda, $74 \%$ dos entrevistados classificaram crimes relacionados à segurança e saúde no trabalho como mais graves; $60 \%$ opinaram que a fixação de preços era uma ofensa grave; e menos da metade dos respondentes tinha crenças similares sobre insider trading (SIMPSON, 2002).

A pesquisa realizada por Miller, Rossi, e Simpson (199I) mostra que os entrevistados acreditam que as sanções devam ser mais severas quando a vítima ou o infrator é uma corporação, e não um indivíduo. No entanto, as atitudes punitivas variam de acordo com grau de exploração e da culpabilidade do ato. Pesquisas com executivos e autoridades da justiça criminal também mostram variações semelhantes nas percepções em relação à gravidade do crime de colarinho branco e punição adequada. Assim, viu-se que a punição do crime não leva em consideração apenas o que se está acusando, mas o histórico criminal dessas organizações e as consequências das ações. 
É necessário mostrar para o público que os crimes corporativos são mais graves do que crimes convencionais e apelar para a aplicação de uma adequada sanção aos criminosos. Existem várias razões pelas quais os comportamentos criminosos corporativos não sejam considerados como imorais pelo consenso da comunidade. A pesquisa bibliográfica mostra que a moral é uma importante questão que influencia a opinião pública em relação à gravidade dos crimes corporativos, independentemente de idade, gênero, raça, nacionalidade, religião ou de renda de um indivíduo. Além disso, ficou claro que as pessoas são propensas a pensar no combate dos crimes muito em termos de seus aspectos legais, e muito pouco em termos de sua comunidade ou de fontes culturais. Mesmo quando há um acordo entre a opinião pública de que o comportamento é injusto e imoral, não é provável que seja tenha unanimidade de opinião quanto ao que deve ser feito com a organização ou indivíduo agressor (FULLER, I942).

Em síntese, a opinião pública sobre a gravidade e a punição dos crimes corporativos desempenha papel relevante para que leis sejam definidas. A sociedade civil pode fazer frente a acontecimentos de grande repercussão (ALMOND, 2009; PAYNE, 2012), mesmo que as pressões sejam mais expressivas quando se tratam de crimes nas ruas (UNNEVER; BENSON; CULLEN, 2008). 


\section{PROCEDIMENTOS METODOLÓGICOS}

De acordo com o critério de classificação proposto por Vergara (2004), quanto à natureza, esta pesquisa classifica-se como uma pesquisa quantitativa, a qual, segundo Lakatos e Marconi (2007), consiste em um estudo estatístico que procura apontar determinadas características, medindo numericamente os levantamentos realizados acerca de um problema de pesquisa. Além disso, a pesquisa quantitativa é utilizada quando a proposta é verificar se os dados mensuráveis adquiridos em uma amostra são estatisticamente válidos para o universo do qual a amostra foi retirada, o que se pretendeu neste estudo, pois, por meio do teste de Qui-Quadrado, foram realizados os testes das hipóteses do estudo. Quanto aos fins, este estudo é classificado como uma pesquisa descritiva, a qual, segundo Gil (2002), expõe características de determinada população ou de determinado fenômeno, podendo também estabelecer correlação entre variáveis e definir sua natureza, o que se pretendeu neste estudo.

Uma vez que o objetivo desta pesquisa é caracterizar a opinião dos estudantes de graduação na área de negócios, de instituições públicas e privadas, delimitadas na cidade de Uberlândia/MG, a respeito dos crimes e ilegalidades corporativas, buscando a compreensão do que impulsiona as atuais percepções desse público sobre questões associadas ao tema, estabeleceu-se como público-alvo estudantes do $\mathrm{I}^{\circ}$ ao $\mathrm{Io}^{\circ}$ período de graduação em cursos na área de negócios, tanto de instituições públicas quanto de privadas, selecionando-se uma amostra de estudantes de cursos de Administração, Ciências Contábeis, Gestão da Informação e Tecnólogo de Gestão, tendo como referência o universo constituído pela totalidade dos alunos inscritos no ensino superior no ano letivo de 2015. Vale mencionar que o universo de pesquisa foi centrado apenas para instituições públicas e privadas localizadas na cidade de Uberlândia-MG. A amostra representativa de cada curso inclui 500 alunos ao todo, sendo 200 estudantes de Administração, Ioo de Ciências Contábeis, Ioo de Gestão da Informação e roo estudantes de cursos Tecnólogos em gestão. As amostras foram escolhidas aleatoriamente, segundo critério de representatividade não probabilística por conveniência, ou seja, pela facilidade de acesso aos pesquisados (VERGARA, 2004). 
Os dados foram coletados por meio de um questionário estruturado composto por 19 questões de múltipla escolha e uma questão com escala na ordem de importância de I a 5 . O questionário desta pesquisa foi disponibilizado na plataforma do Google Docs, cujo link foi enviado por e-mail e por redes sociais para que os estudantes respondessem. Como complemento da quantidade de amostra selecionada, alguns questionários foram impressos para a aplicação direta com os estudantes das instituições privadas, o que foi realizado em sala de aula. Antes da aplicação dos questionários realizou-se um pré-teste com io estudantes de cada um dos cursos, a fim de se verificar possíveis problemas e ambiguidades do questionário elaborado. Após esta fase, alcançou-se a versão final do mesmo.

A coleta de dados foi realizada durante os meses de janeiro, fevereiro e março de 2015. A opção "Outros" na questão do curso que o estudante faz serviu como critério para eliminação de respondentes que não se encaixariam no objeto de estudo desta pesquisa, ou seja, foram descartadas as respostas de estudantes que não faziam algum curso relacionado à área de gestão.

Logo após, as hipóteses foram testadas com base em inferência estatística, aplicando-se teste de Qui-Quadrado de independência com um nível de significância de 5\%, com a utilização dos Softwares BioEstat 5.3 e o spss 20. As observações encontradas foram representadas por meio de figuras e tabelas. Além disso, buscou-se fazer uma discussão dos resultados obtidos com a literatura pesquisada. No processo de tabulação dos dados, 26 respostas foram descartadas por problemas de preenchimento ou por não se enquadrarem no objeto de estudo da pesquisa. Desse modo, das 470 respostas obtidas, 444 foram validadas, representando uma taxa de resposta de $89 \%$ em relação à amostra desejada.

O questionário foi elaborado considerando-se a revisão da literatura sobre a opinião pública quanto aos crimes corporativos e as variáveis que podem influenciar essa opinião quando se trata de estudantes dos cursos da área de gestão. $\mathrm{O}$ instrumento considerou as seguintes variáveis:

Conhecimento sobre Crimes Corporativos: refere-se à percepção do estudante sobre o nível de conhecimento que o respondente possui sobre 
o tema de crimes corporativos, bem como o fato de acompanhar ou não notícias a respeito e as causas que acredita estarem associados a essas práticas.

Gravidade dos Crimes Corporativos: essa variável se refere à percepção de gravidade dos estudantes para I4 exemplos de ações criminosas, escolhidas com base em situações que mais aparecem na mídia e conforme a pesquisa de ALMOND (2009), bem como a noção de gravidade dos estudantes em relação aos crimes corporativos e os crimes de rua.

Interesse ao Combate dos Crimes Corporativos: essa variável referese ao papel que o estudante, enquanto futuro gestor entende que deva desempenhar para evitar esses tipos de ações; além de suas opiniões a respeito das punições sobre estas práticas criminosas.

Curso: é a variável que define em qual área de gestão o estudante está se graduando. As possíveis alternativas são: Administração, Ciências Contábeis, Gestão da Informação e Tecnólogo de gestão.

Período: é a variável que mostra em qual nível o estudante se encontra na graduação. As possíveis alternativas são: $\mathrm{I}^{\circ}$ ao $10^{\circ}$ para cursos com duração de cinco anos, $\mathrm{I}^{\circ}$ ao $8^{\circ}$ para cursos com duração de quatro anos e $\mathrm{I}^{\circ}$ ao $4^{\circ}$ para cursos com duração de dois anos. Para facilitar a tabulação dos dados, esses períodos foram agrupados em três categorias: início, meio e fim.

Gênero: essa variável apresenta três possíveis alternativas: feminino, masculino e outro.

Instituição: essa variável apresenta duas alternativas: pública e privada.

\section{HIPÓTESES DE PESQUISA}

Com base na literatura estudada sobre a opinião pública quanto aos crimes corporativos, são levantadas algumas hipóteses sobre fatores que podem influenciar a interpretação individual em relação a esse tema.

De acordo com Santos, Guevara e Amorim (2013), quanto maior o grau de instrução de uma pessoa, maior tende a ser sua percepção do que é certo e errado. Desse modo, o grau de instrução de um indivíduo reflete o tempo dedicado aos estudos e ao contato com tópicos abrangentes, como crimes corporativos. Dessa forma, acredita-se que o grau de escolaridade e o conteúdo estudado influenciam positivamente no conhecimento 
do indivíduo sobre essa temática, bem como o papel que esse percebe desempenhar no combate ao crime corporativo. Assim, lança-se mão das seguintes hipóteses de pesquisa:

Ho: O conhecimento independe do curso | Hr: O conhecimento depende do curso Ho: O conhecimento independe do período $\mid$ Hr: O conhecimento depende do período Ho: O papel a ser desempenhado independe do curso | Hr: O papel a ser desempenhado depende do curso

Ho: O papel a ser desempenhado independe do período | Hr: O papel a ser desempenhado depende do período

De acordo com Stylianou (2003), as pesquisas sobre a opinião pública envolvendo crimes servem para identificar quais delitos são considerados mais graves e quais características dos indivíduos moderam essas percepções. Sendo assim, torna-se interessante avaliar as características do gênero e idade dos estudantes, bem como o local em que esses estudam para compreender se existem diferenças nas percepções em relação à gravidade dos crimes corporativos. Assim, considerou-se apropriado avaliar as seguintes hipóteses:

Ho: A gravidade independe da instituição | H1: A gravidade depende da instituição

Ho: A gravidade independe do gênero | H1: A gravidade depende do gênero

Ho: A gravidade independe da idade | H1: A gravidade depende da idade

O perfil dos estudantes pesquisados está detalhado na Tabela I. Para cada uma das seguintes variáveis: (a) conhecimento sobre crimes corporativos, (b) gravidade dos crimes corporativos e (c) interesse ao combate dos crimes corporativos, foram verificadas as associações com as outras variáveis: (I) curso, (2) idade (3) período, (4) tipo de instituição e (5) gênero. Para verificar a associação entre as variáveis realizou-se a combinação de todas as variáveis duas a duas, dispondo-as em uma tabela de dupla entrada, denominada de tabela de contingência. O teste de Qui-quadrado de independência foi aplicado, cuja hipótese nula (Ho) testada foi de que a variável pertencente na coluna independe da variável representada na linha. Enquanto na hipótese alternativa (HI) foi testada a hipótese de que a variável pertencente na coluna depende ou tem associação com a variável linha. 


\section{APRESENTAÇÃO E ANÁLISE DOS RESULTADOS}

Nesta seção, apresentamos os resultados da pesquisa em quatro subseções. Inicialmente, oferecemos uma visão geral do perfil dos participantes da pesquisa. Em seguida, na segunda parte, apresentamos o grau de conhecimento dos pesquisados quanto aos crimes e ilegalidades corporativas. $\mathrm{Na}$ terceira parte, discutimos os resultados obtidos quanto à gravidade dos crimes corporativos na visão dos pesquisados. Na quarta parte, apresentamos o nível do interesse ao combate dos crimes corporativos por parte dos pesquisados. Por fim, na quinta parte, oferecemos uma síntese dos resultados.

\section{PERFIL DOS ENTREVISTADOS}

$\mathrm{Na}$ Tabela I apresenta-se o perfil dos estudantes participantes da pesquisa.

Tabelar Perfil dos estudantes que participaram da pesquisa

\begin{tabular}{|llll|}
\hline Variável & Descrição & Frequência Absoluta & Frequência Percentual \\
\hline Idade & 18 a 24 anos & 334 & $75 \%$ \\
& 25 a 31 anos & 75 & $17 \%$ \\
& Mais de 32 anos & 35 & $8 \%$ \\
\hline Curso & Administração & 207 & $47 \%$ \\
& Gestão da Informação & 70 & $16 \%$ \\
& Ciências Contábeis & 93 & $21 \%$ \\
\hline Período & Tecnólogo & 74 & $16 \%$ \\
& $1^{\circ}$ & 29 & $6 \%$ \\
& $2^{\circ}$ & 34 & $8 \%$ \\
& $3^{\circ}$ & 83 & $19 \%$ \\
& $4^{\circ}$ & 36 & $8 \%$ \\
& $5^{\circ}$ & 52 & $12 \%$ \\
& $6^{\circ}$ & 39 & $9 \%$ \\
& $7^{\circ}$ & 43 & $10 \%$ \\
& $8^{a}$ & 54 & $12 \%$ \\
\hline Instituição & $9^{\circ}$ & 28 & $6 \%$ \\
& $10^{\circ}$ & 46 & $10 \%$ \\
\hline Gênero & Pública & 294 & $66 \%$ \\
& Privada & 150 & $34 \%$ \\
\hline & Feminino & 237 & $53 \%$ \\
\hline
\end{tabular}


A maioria (75\%) dos respondentes está na faixa de i8 a 24 anos e 53\% são mulheres. Além disso, a maioria (66\%) dos estudantes participantes da pesquisa estuda em instituição pública. É importante mencionar que estudantes do curso de Gestão da Informação são de instituição pública e todos os Tecnólogos (de recursos humanos, marketing e finanças) estudam em instituições privadas. Apesar de $47 \%$ dos 444 estudantes pesquisados estarem no curso de Administração, há presença de respondentes em todos os períodos de graduação, bem como se obteve quase a mesma quantidade de respondentes dos gêneros feminino e masculino.

Na seção seguinte, descrevem-se os resultados obtidos sobre o nível de conhecimento que os respondentes têm sobre crimes corporativos.

\section{CONHECIMENTO SOBRE CRIMES CORPORATIVOS}

A segunda parte do questionário tem como objetivo investigar o conhecimento dos respondentes sobre os crimes corporativos. A maioria dos estudantes (59\%) acredita ter nível médio de conhecimento adquirido de notícias e assuntos da atualidade que envolve o tema. Apenas $6 \%$ da amostra acreditam ter um nível alto de conhecimento, sabendo o significado, implicações e sempre procurando acompanhar informações relacionadas a crimes corporativos. Já $35 \%$ dos pesquisados acreditam possuir nível baixo de conhecimento, tendo pouco ou nenhum conhecimento sobre a temática. Rebovich e Kane (2002) colocam que esta falta de conhecimento do público atrapalha no combate aos crimes, além de mostrar o desdém público quanto aos crimes cometidos por corporações. Portanto, é essencial que essa temática seja mais discutida no meio social de forma a aumentar o interesse da população, ao passar a enxergar as consequências que tais crimes e ilegalidades podem trazer à sociedade em geral.

A idade não é um fator que afeta o nível do conhecimento dos estudantes em relação à temática de crimes corporativos, visto que a hipótese nula de independência das variáveis idade e conhecimento dos crimes corporativos não foi rejeitada pelo teste de Qui-quadrado ( $\mathrm{p}>0,05)$. Porém, o curso é uma variável que afeta o nível de conhecimento dos estudantes a respeito da temática de crimes corporativos, pois se percebe que estudantes do curso de 
Administração tendem a ter um nível de conhecimento proporcionalmente mais alto em relação aos outros cursos.

Por meio do teste de Qui-Quadrado fica claro que o período também é uma variável que influencia o nível de conhecimento dos estudantes. Dessa forma, pode-se afirmar que, quanto mais próximo do término do curso, maior tende a ser o nível de conhecimento dos estudantes sobre assuntos relacionados à temática de crimes nas organizações. É interessante mencionar que nenhum estudante que se encontrava no início do curso afirmou possuir alto conhecimento. O nível de conhecimento dos pesquisados também está associado à instituição que esses estudam, uma vez que $\mathrm{p}<0,05$. Assim, estudantes de instituição pública parecem ter mais conhecimento sobre o assunto do que estudantes de instituições particulares. Além disso, o nível baixo de conhecimento de estudantes de instituições públicas foi praticamente a metade das respostas, se comparado com os estudantes de instituições particulares. E, por fim, o nível de conhecimento também tem associação com o gênero do estudante, pois $\mathrm{p}<0,05$. Desse modo, os estudantes do gênero masculino têm um conhecimento sobre o assunto $67 \%$ maior do que os estudantes do gênero feminino, considerando o nível alto de conhecimento.

A maioria (66\%) dos pesquisados disseram ter ouvido ou lido notícias, recentemente, a respeito de crimes corporativos, sendo a mídia (jornais, revistas e sites) o principal meio. Rebovich e Kane (2002) destacam que a cobertura da mídia sobre o crime corporativo pode afetar a opinião pública sobre o entendimento desse assunto. Portanto, se a maioria dos estudantes apresenta um médio ou baixo conhecimento sobre o assunto pode ser decorrente do fato do crime corporativo não ser tão discutido na mídia que acessam. Ainda a esse respeito, Medeiros e Alcadipani (2013) apontaram a parcialidade da mídia como um dessas causas.

Quanto à forma de obtenção de conhecimento sobre o assunto, $19 \%$ dos estudantes afirmou ter conhecimento sobre o assunto por meio de conhecidos (amigos, familiares e colegas de trabalho) e/ ou discussão em sala de aula. Apenas I\% dos estudantes respondeu ter lido recentemente artigos de blogs ou matérias em televisão sobre o tema. A discussão em sala de aula 
sobre crimes corporativos foi mencionada principalmente por estudantes do gênero feminino, de I8 a 24 anos, do curso de Administração, de instituição pública e que estão nos últimos períodos. É importante mencionar que nenhum estudante de Ciências Contábeis apontou que essa temática havia sido discutida em sala de aula.

A ineficácia da justiça brasileira (por falta de maior fiscalização, por exemplo), competição intensa e pressão por desempenho são as três principais razões apontadas pelos estudantes como motivos para que as organizações cometam crimes e ilegalidades. A existência de empregados altamente comprometidos, a baixa competitividade e os altos níveis de inovação foram os motivos menos apontados pelos estudantes.

As causas associadas às leis governamentais e questões políticas foram destacadas, principalmente, por estudantes de instituição privada e idade superior a 25 anos. Em relação ao gênero, há contraposição em algumas causas apontadas entre estudantes de gênero masculino e feminino, como, por exemplo, os primeiros apontam para a baixa competitividade, enquanto os segundos mencionam a competição intensa como uma das principais causas dos comportamentos criminosos nas organizações. Do mesmo modo, estudantes do gênero masculino apontam para a alta inovação nas estruturas e processos, enquanto aqueles do gênero feminino apontam para a alta sucessão, ou seja, a quantidade de hierarquias no organograma tradicional da organização. Mais de 70\% de estudantes em cursos de Tecnólogo atribuem à ineficácia da justiça brasileira como a principal causa. E, por fim, o período do curso é a variável que não apresentou nenhuma característica particular.

De modo geral, os crimes corporativos não se constituem em uma temática ignorada pelos respondentes, embora o nível de conhecimento seja médio. Na seção seguinte, apresentam-se os resultados obtidos quanto à opinião dos pesquisados sobre a gravidade do crime corporativo.

\section{OPINIÃO SOBRE A GRAVIDADE DO CRIME CORPORATIVO}

A terceira parte do questionário é dirigida para conhecer a opinião dos pesquisados quanto à gravidade do crime corporativo. Os pesquisados atribuíram notas para I4 tipos de ilegalidades e crimes que podem acontecer 
nas organizações, sendo nota i para uma situação pouco grave, e 5 para uma situação muito grave. Diante disso, notou-se que os estudantes consideram o "uso de mão de obra infantil e trabalho escravo" como os tipos de crimes mais graves, cuja média de notas foi 4,82. Por outro lado, o recall de produtos foi apontado como a situação menos grave, obtendo uma média de notas de 3,I3. A média geral para todas as I4 situações é apresentada na Tabela 2. Para simplificar a análise, os tipos de ilegalidades e crimes foram divididos em quatro categorias, conforme as principais vítimas: crime de ordem ambiental, ilegalidade e crime contra o trabalhador, ilegalidade contra o consumidor e crime contra o governo, de acordo com as classificações apresentadas por Grabosky e Braithwaite (1987) e Schrager e Short (1978).

De acordo com a distinção proposta por Baucus e Dworkin (I99I) entre ilegalidade corporativa e crime corporativo, pode-se observar que apenas as situações de "Jogar dejetos da produção em nascentes"; "Casos do assédio moral e sexual no ambiente de trabalho"; "Uso de mão de obra infantil e trabalho escravo" e "Organizações que possuem atividades consideradas ilegais como: jogos de azar, vendas de drogas" são consideradas como crimes perante a jurisdição brasileira e, portanto, são tratadas na vara criminal. $\mathrm{Na}$ pesquisa, todas essas estão entre as cinco situações tidas como de maior gravidade na visão dos estudantes.

Tabela 2 Notas atribuídas aos I4 tipos de ilegalidades e crimes organizacionais

\begin{tabular}{|l|l|}
\hline Situação & Média Geral \\
\hline Jogar dejetos da produção em nascentes & 4,71 \\
\hline Não pagar hora extra & 4,32 \\
\hline Cobrar indevidamente faturas de consumidores & 4,27 \\
\hline Deixar de pagar impostos municipais, estaduais e federais & 3,99 \\
\hline Fabricação e venda de produtos que podem ser prejudicais para os usuários & 4,46 \\
\hline $\begin{array}{l}\text { Contaminar de forma consciente alimentos que resulta em morte ou problemas } \\
\text { para pessoas }\end{array}$ & 4,80 \\
\hline Fazer propaganda enganosa de produtos & 4,01 \\
\hline $\begin{array}{l}\text { Ocorrência de acidente de trabalho com operador de máquinas por falta de } \\
\text { equipamentos de segurança }\end{array}$ & 4,52 \\
\hline Declaração falsa de informações financeiras & 4,17 \\
\hline
\end{tabular}




\begin{tabular}{|l|l|}
\hline Situação & Média Geral \\
\hline Suborno direto ou indireto de funcionários & 4,27 \\
\hline $\begin{array}{l}\text { Casos do assédio moral e sexual no ambiente de trabalho } \\
\text { Uso de mão de obra infantil e trabalho escravo }\end{array}$ & 4,47 \\
\hline $\begin{array}{l}\text { Organizações que possuem atividades consideradas ilegais como: jogos de azar, } \\
\text { vendas de drogas }\end{array}$ & 4,82 \\
\hline Recall de produtos & 3,13 \\
\hline
\end{tabular}

Os estudantes com idade de 18 a 24 anos tendem a considerar que ilegalidades cometidas contra o governo e consumidor são menos graves do que os outros tipos de ilegalidades, pois a média de notas atribuídas para essas situações foi menor que quatro. Os estudantes com idade superior a 32 anos, em contrapartida, se preocupam mais com esses aspectos. Estudantes que cursam Gestão da Informação consideraram as ilegalidades contra os consumidores como mais graves, se comparado com os pesquisados de outros cursos. Por outro lado, observou-se que estudantes que cursam Ciências Contábeis atribuem maior importância para crimes organizacionais contra o governo. Nenhuma associação foi encontrada entre a idade e curso dos pesquisados e a nota especialmente atribuída a respeito dos crimes e ilegalidades contra o trabalhador.

Já em relação à instituição, estudantes de instituições privadas apresentaram maior média nas notas atribuídas para crimes contra o governo; enquanto estudantes de instituição pública avaliaram como mais grave as ilegalidades e crimes contra trabalhadores e consumidores. Curiosamente, os pesquisados que estavam no começo do curso atribuíram maior gravidade para a maior parte das situações, se comparados com os estudantes que estavam no meio ou no fim de seus cursos. Estudantes de Gestão da Informação do gênero feminino, com idade superior a 32 anos, que estão no começo do curso e em instituição pública representam a parcela dos estudantes que mais se preocupam com crimes de ordem ambiental. E, por fim, quanto ao gênero, notou-se que estudantes do gênero feminino tiveram uma média de notas maiores para todas as situações.

A percepção de gravidade dos estudantes das I4 ações avaliadas foi baseada, principalmente, pela consequência das ações para pessoas, ambiente interno 
e externo organizacional e a questão ética e moral envolvida, representando $65 \%$ e $68 \%$ das escolhas dos pesquisados, respectivamente. Desse modo, os estudantes tendem a confiar no conceito de nocividade percebido ao considerar a gravidade dos crimes corporativos ao invés de considerar as percepções de ilicitude, de acordo com a pesquisa de Rosenmerkel (200I).

Ainda quanto à gravidade dos crimes corporativos, $27 \%$ dos estudantes basearam as suas escolhas no grau de culpa da organização envolvida. Essa justificativa foi apresentada por Warr (1989) e Tversky e Kahneman (1974) como o principal aspecto utilizado pelo público quando irá classificar a gravidade de um crime. Outros $18 \%$ dos pesquisados utilizaram como base o fato de terem passado por alguma experiência parecida ou ter tido conhecimento de algum desses fatos ocorridos. E, por fim, dois estudantes mencionaram terem escolhido a gravidade conforme a capacidade da organização para burlar as leis para cada um dos fatos e a percepção de gravidade aprendida na "mídia" para essas ações.

$\mathrm{Na}$ opinião da maioria ( $84 \%$ ) dos estudantes, o estupro e assassinato é o tipo de crime mais grave; em segundo lugar, é classificado como mais grave o crime ambiental, representando $8 \%$ das respostas. Os resultados convergem com os achados de pesquisa de opinião pública apontada por Simpson (2002), de que o crime ambiental foi considerado como o crime corporativo mais grave, ficando atrás do assassinato. Apenas $23(5 \%)$ estudantes apontaram a fraude corporativa como o tipo de crime mais grave; e os outros $3 \%$ restantes mencionaram o furto como o tipo de crime de maior gravidade. Dessa forma, conclui-se que os crimes corporativos tendem a receber classificações menos graves pelo público em relação a outros tipos de crimes, conforme apontado por Rosenmerkel (200r).

A última questão do questionário sobre a gravidade perguntava se os estudantes acreditam que o crime cometido por uma empresa é mais grave do que um crime cometido por um indivíduo. A maioria (62\%) deles respondeu que o crime cometido por uma empresa não é mais grave do que um crime cometido por um indivíduo. Assim, de acordo com a maioria dos respondentes, os crimes de rua, como estupro, assassinato e furto são mais graves do que um crime ambiental ou a fraude corporativa. 
Quanto a esse aspecto, não foi encontrada nenhuma associação com os perfis dos estudantes. Porém, estudantes dos cursos de Administração e Gestão da Informação mostraram-se divididos em relação a essa questão, tendo $42 \%$ e $47,1 \%$ dos pesquisados, respectivamente, considerado que o crime corporativo é mais grave.

Os resultados apontam que os crimes de rua são considerados mais graves para a maioria dos respondentes, o que pode influir no interesse da população no combate dos crimes corporativos. A seção seguinte traz os resultados sobre essa temática.

\section{INTERESSE NO COMBATE DOS CRIMES CORPORATIVOS}

O interesse ao combate dos crimes corporativos constitui o tema da última parte do questionário. Quando se perguntou aos estudantes se eles deixariam de ser clientes ou trabalhar em uma empresa que estava sendo acusada de cometer certo tipo de crime, as respostas ficaram bem divididas; $33 \%$ deles afirmaram que sim, mas somente se a empresa fosse considerada legalmente culpada. Já outros 30,8\% apontaram que isso dependeria de qual ação a empresa estava sendo acusada. Por outro lado, $15 \%$ dos estudantes disseram que deixariam de ser clientes e trabalhar, independentemente, se a empresa fosse legalmente considerada culpada ou não; e outros 66 (15\%) estudantes já colocaram que essa situação depende do histórico de ilegalidades e crimes já cometidos pela organização, ou seja, se houve reincidência ou não, indo ao encontro das observações constatadas em Miller, Rossi, e Simpson (I99I). E, por último, apenas $7 \%$ dos pesquisados disseram que continuariam a trabalhar e ser clientes dessa empresa, mesmo que a justiça a condenasse como criminosa.

Quanto ao interesse sobre crimes corporativos, 44\% dos pesquisados disseram que sabem ou têm interesse em saber como e onde denunciar uma empresa que praticasse alguma ilegalidade; outros $39 \%$ já disseram possuir ou têm interesse em obter algum conhecimento das leis referentes ao Código de Defesa do Consumidor. Ainda, $20 \%$ dos estudantes disseram que participam ou têm interesse em participar de algum movimento de proteção ao meio-ambiente; e II\% apontaram que participam ou possuem interesse em participar de algum sindicato referente à sua categoria trabalhista. 
O desinteresse também foi apontado nas respostas de 67 (15\%) estudantes que afirmaram não ter interesse algum sobre essa temática. Essa parcela considerável aponta para o papel omisso da sociedade em geral, que, conforme Medeiros (2013), também acaba contribuindo de algum modo para o acontecimento desses tipos de crimes e faz com que essas práticas sejam internalizadas como "normal". Além disso, o desinteresse dos estudantes pela temática reflete a necessidade de estimulá-los a terem uma visão mais crítica e reflexiva sobre o assunto.

O interesse em saber como denunciar organizações que praticam alguma ilegalidade é maior nos estudantes do gênero masculino com idade superior a 32 anos e, principalmente, de instituição pública e que cursam Gestão da Informação. A maioria dos estudantes do gênero feminino que cursa Ciências Contábeis ou Administração apresenta um forte interesse em relação à proteção ambiental ou nenhum interesse sobre o combate de crimes corporativos. Além do mais, o interesse em conhecer as leis referentes ao Código de Defesa do Consumidor e a participação em algum sindicato é muito forte em estudantes de instituições privadas e que fazem algum curso em Tecnólogo de Gestão.

Quanto ao aspecto relacionado à legislação, $36 \%$ dos estudantes acreditam que as leis são insuficientes no combate aos crimes corporativos e que é necessário um maior envolvimento da sociedade em geral, principalmente, não sendo omissa aos fatos e à presença de mais movimentos sociais. Portanto, conforme foi apontado por Vergara e Branco (200I), há necessidade da existência de mais pessoas que não sejam indiferentes a essas situações e que tenham uma abordagem holística no trato das organizações.

A aplicação de advertências e, em casos mais graves, prisões, foi destacada por 44 (10\%) estudantes como forma de combate aos crimes, principalmente, aqueles que se encontram no período final de seus cursos. Porém, 55 (I $2 \%)$ pesquisados apresentaram a educação como meio de combate ao crime corporativo, e, assim, sugeriram que seja feita uma reforma de base, em que, desde os períodos iniciais de educação, os professores estariam constantemente reforçando para os estudantes a importância de agir de forma ética. Esses aspectos vão ao encontro dos resultados da pesquisa de Santos, Guevara e Amorim (2013) de que, quanto maior o grau de instrução 
de uma pessoa, maior tende a ser sua percepção do que é certo ou errado, por isso, uma maneira de tentar acabar com a corrupção e outros crimes nas organizações é investir em capacitações para que as pessoas tenham mais conhecimentos sobre esse assunto. O autor também coloca as ações de governança corporativa como uma das maneiras de se tentar acabar com a corrupção nas organizações, contudo, nenhum estudante citou esse aspecto.

$\mathrm{O}$ interesse no combate dos crimes corporativos mostrou ter alguma relação ( $\mathrm{p}<0,05$, rejeição de Ho) com o curso e período dos pesquisados. Assim, estudantes de Administração e Ciências Contábeis e que estão mais da metade do curso acreditam, em grande parte, que as leis são insuficientes no combate; enquanto que estudantes de Gestão da Informação e Tecnólogo e que estão no início do curso acreditam que a solução está na lei, apesar de essa ser muito ambígua e insuficiente. Portanto, é difícil determinar quem são os verdadeiros culpados, bem como conseguir distinguir as ações civis das criminais, conforme apontado por Schrager e Short (1978) quanto à dificuldade existente em se estabelecer a intenção criminal quando se trata de organizações. Já a idade, instituição e gênero não mostraram ter relação ( $p>0,05$, não rejeição de Ho) com o interesse no combate aos crimes corporativos, pois nenhuma diferença significativa foi encontrada entre as respostas.

Quando se perguntou aos estudantes qual é o papel a ser desempenhado pelo profissional formado na área de negócios quanto ao combate dos crimes corporativos, a maioria (65\%) disse denunciar; $20 \%$ afirmaram que o profissional deve procurar alternativas para resolver esse aspecto; $8 \%$ disseram que o melhor papel para o profissional é negar-se a participar de tais atos. Além disso, dois estudantes destacaram ser importante que o profissional repreenda esse tipo de prática. Por outro lado, 4\% dos pesquisados disseram que o profissional não pode fazer nada a respeito, pois tem limitações na sua atuação; e outros 3\% apontaram que o profissional apenas deverá cumprir ordens, o que remete à análise de Alcadipani e Medeiros (20I3) sobre a banalidade do mal nos crimes corporativos.

A opinião dos estudantes sobre o papel do futuro gestor não tem associação ( $\mathrm{p}>0,05$, não rejeição de Ho) com nenhuma das variáveis: idade, curso, instituição, período e gênero. Contudo, o papel de negar é fortemente 
colocado por estudantes com idade de 25 a 3r anos. Os estudantes do gênero masculino acreditam mais no papel de procurar alternativas como forma de combate aos crimes e ilegalidades nas organizações. Já a ideia de que o gestor deverá apenas cumprir ordens é mais forte naqueles que estudam em instituições privadas; além de que o fato de não poder fazer nada, devido à limitação na atuação do gestor, não foi apontado por nenhum estudante que estava cursando os primeiros períodos.

A maioria (mais de 50\%) dos pesquisados, principalmente estudantes de Tecnólogo em gestão em instituição privada, com idade média de 25 a 3I anos e do gênero feminino, acredita que a punição do crime corporativo deverá ser mais rigorosa quando a vítima ou infrator for uma pessoa ou organização. Porém, mais de $20 \%$ dos estudantes acreditam que a punição a ser adotada não deverá ser mais rigorosa, dependendo de determinada vítima ou infrator, o que vai de acordo com a pesquisa de Rebovich e Kane (2002). Esses estudantes são, principalmente, do curso de Gestão da Informação de instituição pública, com idade média de I8 a 24 anos e que estão começando o seu curso. As relações com os perfis dos pesquisados e essas apontam que estudantes de instituição privada estão preocupados com a organização como vítima, enquanto aqueles de instituição pública tendem a focar no indivíduo para a aplicação de sanções. Além do mais, alguns cursos, como Ciências Contábeis, apresentaram que a sanção deveria ser mais rigorosa quando a organização fosse vítima, e quando o infrator fosse o indivíduo.

Diferentemente da pesquisa apontada por Miller, Rossi e Simpson (I99I), apenas $8 \%$ dos estudantes, especialmente do gênero masculino e com idade superior a 32 anos, destacaram que a sanção deveria ser mais rigorosa quando a organização fosse vítima; e também I $8 \%$ destacaram que a sanção deveria ser mais rigorosa quando a organização fosse o infrator.

A maioria $(60 \%)$ dos estudantes, principalmente do gênero feminino, com idade média de 25 a 3r anos e que estão cursando Tecnólogo de Gestão, aponta que os executivos das organizações deveriam assumir a culpa pelos crimes ou ilegalidades que eles cometem em nome delas. Contudo, apenas II $(2 \%)$ pesquisados (principalmente do gênero masculino e que estão na metade do curso) disseram que os executivos não deveriam assumir a 
culpa; outros $37 \%$ consideram que esse aspecto depende da situação. Esses últimos são essencialmente estudantes do gênero masculino, que estudam em instituição pública e cursam Administração.

Conforme os autores que escreveram sobre o assunto apontam, os sentimentos do público são potencialmente importantes na formação de políticas de controle dos crimes, especialmente, se esses ocorrem quando "o público expressa sentimentos de que alguma coisa poderia ter sido feita para parar uma onda de crimes corporativos" (UNNEVER; BENSON; CULLEN, 2008, p.r65). Assim, esses resultados apontam para a necessidade de discutir os crimes corporativos com maior profundidade nos cursos que formam futuros gestores.

\section{SÍNTESE DOS RESULTADOS}

A Tabela 3 evidencia quais das hipóteses iniciais do estudo foram comprovadas, de acordo com os resultados expostos anteriormente. Assim, apenas duas hipóteses foram aceitas: o conhecimento sobre o crime corporativo depende do curso e do período do estudante. Portanto, a hipótese Ho relacionada a essas hipóteses foi rejeitada, uma vez que $\mathrm{p}<0,05$.

Tabela 3 Resultado do Teste de Hipótese por meio de Qui-Quadrado

\begin{tabular}{|lll|}
\hline Hipótese Ho & $\begin{array}{l}\text { Comprovação } \\
\text { da Hipótese }\end{array}$ & P-Valor \\
\hline O conhecimento sobre crimes corporativos independe do curso & Não & 0,00 \\
\hline O conhecimento sobre crimes corporativos independe do período & Não & 0,00 \\
\hline A opinião sobre o papel a ser desempenhado independe do curso & Sim & 0,055 \\
\hline A opinião sobre o papel a ser desempenhado independe do período & Sim & 0,080 \\
\hline A percepção de gravidade independe da instituição & Sim & 0,765 \\
\hline A percepção de gravidade independe do gênero & Sim & 0,258 \\
\hline A percepção de gravidade independe da idade & Sim & 0,211 \\
\hline
\end{tabular}

Retomando o objetivo geral desta pesquisa, queé caracterizar a opinião dos estudantes de graduação na área de negócios, percebe-se que os pesquisados reconhecem a gravidade existente no crime corporativo, porém ainda o consideram como menos grave do que os crimes de rua. Quanto ao nível de conhecimento dos estudantes sobre o tema em questão, é possível afirmar que a maioria tem um conhecimento 
médio, e, poucos conhecem, de fato, o significado do termo, suas implicações e procuram sempre acompanhar informações relacionadas à temática. Além disso, estudantes do curso de Administração tendem a ter um nível de conhecimento mais alto; enquanto estudantes de cursos de Tecnólogo em Gestão apresentam, em sua maioria, um conhecimento baixo. Aqueles que estão finalizando o curso e estudam em instituições públicas também acreditam possuir maior conhecimento sobre assunto.

Esta pesquisa identificou ainda a percepção dos pesquisados quanto à gravidade dos crimes corporativos. Os resultados evidenciam que os estudantes atribuíram maiores notas para as ações tidas como crimes pela jurisdição brasileira. As ilegalidades associadas aos consumidores e trabalhadores foram mais pontuadas por estudantes com idade superior a 32 anos e que cursam Gestão da Informação em instituição pública. Já estudantes que cursam Ciências Contábeis atribuem maior importância para crimes organizacionais contra o governo, como a corrupção.

Quanto à opinião dos pesquisados sobre o combate dos crimes corporativos, viu-se que a maioria dos estudantes acredita que as leis são insuficientes no combate aos crimes corporativos e que é necessário um maior envolvimento da sociedade em geral. Além disso, os respondentes reconhecem que o papel do futuro gestor no combate dessas práticas é denunciar. Porém, ainda existe muito desinteresse nesse aspecto, principalmente, por estudantes do gênero feminino, que cursam Administração ou Ciências Contábeis em instituição pública, e, que estão nos períodos finais do curso.

E, por fim, ao estabelecer relações entre as respostas encontradas e os perfis dos pesquisados, a pesquisa mostrou que há uma associação diferente, dependendo de cada um dos três aspectos analisados, assim, por exemplo, a idade não afeta o nível do conhecimento dos estudantes sobre crimes corporativos; enquanto que o fato de o estudante estar em uma instituição pública ou privada não afeta a sua percepção na gravidade de um crime. Além disso, os testes de Qui-Quadrado possibilitaram encontrar novas relações que não faziam parte das hipóteses inicialmente consideradas.

O Quadro I apresenta os principais resultados da pesquisa e uma comparação com a teoria. 
CURSOS DE GRADUAÇÃO DA ÁREA DE NEGÓCIOS

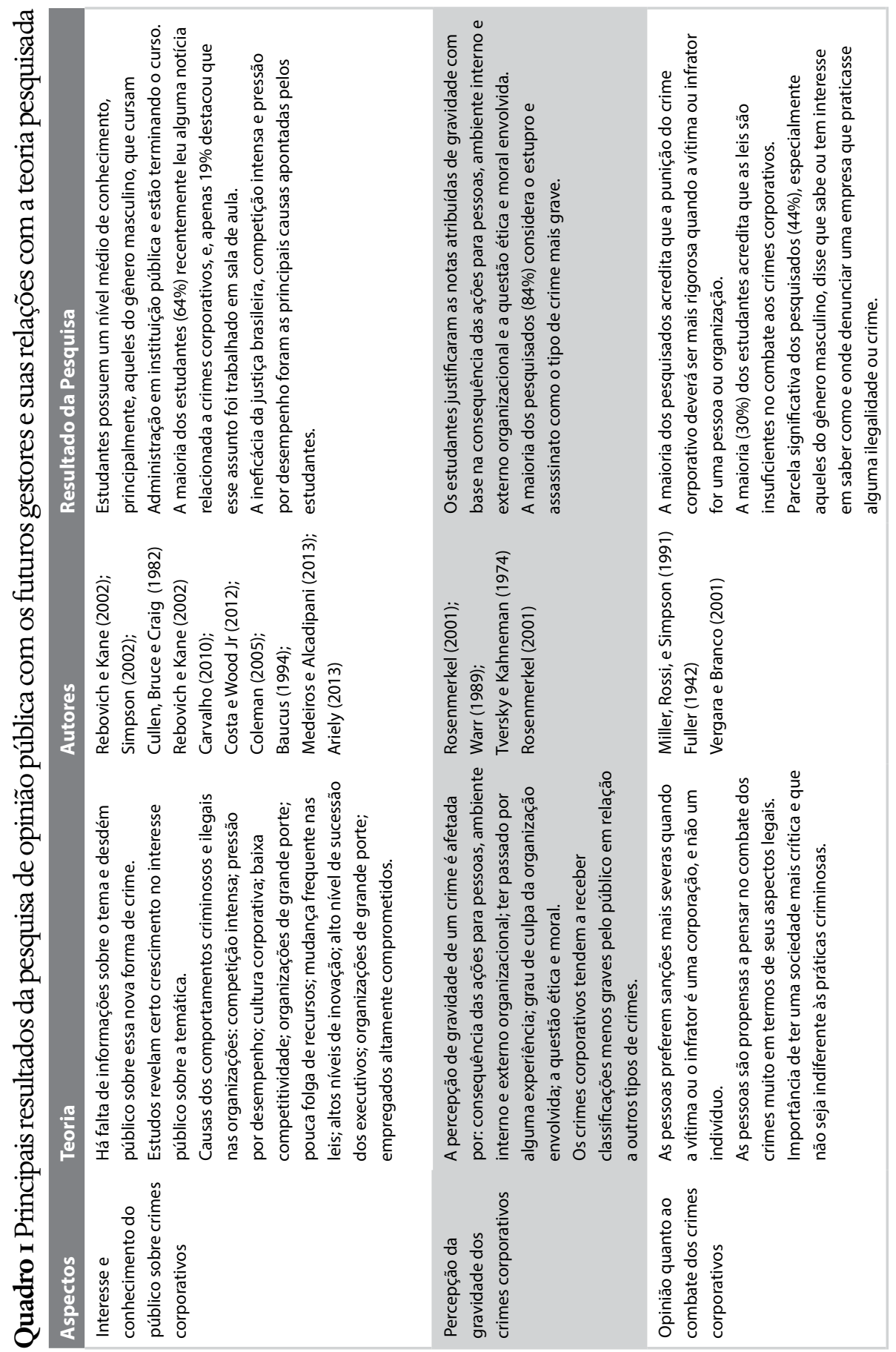


De modo geral, entende-se que os achados desta pesquisa têm correspondência com a literatura pesquisada. Os resultados refletem ainda as inquietações de vários autores. Turner (2005) chama a atenção para se aumentar a consciência pública e envolver estudantes de graduação em Direito e prepará-los para julgarem corretamente os crimes corporativos. Contudo, necessário é expandir para todos os estudantes essa visão. Motta (1983) e Nicolini (2003) procuram despertar a atenção para que as escolas de Administração formem administradores mais críticos da sua realidade social. Thiry-Cherques (2004) avalia as representações dos estudantes de Administração a respeito da questão da ética, e assim, questiona se seria possível o futuro administrador possuir uma consciência moral e conduta ética, pois esses continuam aprendendo que o lucro da organização deve estar aliado a qualquer outro aspecto.

Os resultados desta pesquisa vão ao encontro das críticas dirigidas à formação de administradores e executivos (BENNIS; O'TOOLE, 2005; GHOSHAL, 2005; MITROFF, 2004; PFEFFER; FONG, 2002; GIOIA, 2002), sugerindo que os responsáveis pelas propostas pedagógicas dos cursos reflitam sobre as lacunas existentes quanto à educação desses profissionais, considerando o atual cenário empresarial, em que crimes, esquemas de corrupção, trabalho escravo, entre outras práticas da mesma natureza tornam-se, cada vez mais presentes nas notícias comuns na mídia em geral, e permanecem ausentes na pauta dos conteúdos curriculares. 


\section{CONSIDERAÇÕES FINAIS}

Esta pesquisa teve como propósito caracterizar a opinião dos estudantes de cursos de gestão acerca do conhecimento que possuem sobre o tema, suas percepções de gravidade com relação aos crimes e ilegalidades cometidos por organizações, bem como o papel que compreendem desempenhar no combate dessas ações.

O modelo de gestão das organizações ainda é pautado na instrumentalidade e racionalização, o que faz com que a exploração do trabalho alheio seja pensada no intuito de obter lucro apenas e não se pensa nas questões éticas envolvidas. Assim, é oportuno estimular a crítica nos jovens administradores para que esses pensem no futuro e na construção de uma sociedade melhor, uma vez que os valores desempenham um papel importante na transformação social das organizações. A educação é a base para que a ética em relação aos crimes corporativos seja bem compreendida e aplicada no contexto organizacional (THIRY-CHERQUES, 2004; ALCADIPANI; BERTERO, 20I2; BORGES; MEDEIROS, 20I4).

Em geral, há um nível médio de conhecimento dos estudantes sobre a temática de crimes corporativos. Além disso, observou-se, por meio desta pesquisa, que apenas a idade não afeta o conhecimento dos estudantes, mas que o curso, período, instituição e gênero influenciam essa variável, e, portanto, as hipóteses inicialmente levantadas foram confirmadas. Os estudantes apontaram a ineficácia da justiça brasileira, competição intensa e pressão por desempenho como os principais motivos para as organizações cometerem crimes e ilegalidades. Assim, os resultados desta pesquisa não indicam um total desdém público em relação à temática de crimes corporativos, como havia sido mencionado por Rebovich e Kane (2002) e Cullen, Bruce e Craig (1982).

Em relação à gravidade, os estudantes consideram o "uso de mão de obra infantil e trabalho escravo" como o crime corporativo de maior gravidade em relação a outros crimes e ilegalidades corporativas. Notouse que a percepção de gravidade dos estudantes é afetada pelo gênero e idade, porém a instituição na qual estudam não apresenta influência. Além disso, a nota atribuída para a gravidade de uma ação é baseada, 
principalmente, na consequência das ações para pessoas, ambiente interno e externo organizacional e a questão ética e moral envolvida. Contudo, eles ainda consideram os crimes de rua como mais graves do que os crimes corporativos, assim como mencionado por Rosenmerkel (200I).

Quanto ao interesse sobre crimes corporativos, a maioria mostrou ter interesse em saber como denunciar uma empresa que cometesse alguma ilegalidade ou crime e acredita que as leis sejam insuficientes no combate aos crimes corporativos. Assim, os estudantes veem que o papel a ser desempenhado pelo profissional na área de negócios é denunciar as práticas ilegais e criminosas que presenciarem nas organizações, bem como acreditam que os executivos devam assumir a culpa pelos crimes que cometem em nome das organizações. Além disso, as hipóteses iniciais sobre o papel do futuro gestor não foram comprovadas.

E, por último, os pesquisados acreditam que a punição do crime corporativo deverá ser mais rigorosa quando a vítima ou infrator for uma pessoa ou organização. Contudo, conforme Fuller (1942), ainda há necessidade de convencer os estudantes de que os crimes corporativos são mais graves do que crimes convencionais e apelar para a aplicação de uma adequada sanção aos criminosos, pois a ideia de que o gestor deverá apenas cumprir ordens ainda é muito forte naqueles que estudam em instituições privadas.

Este estudo tem contribuições teóricas e práticas. Quanto às contribuições práticas, este estudo oferece informações sobre o interesse e a opinião de estudantes sobre as condutas corporativas criminosas e ilegais, as quais têm se tornando cada vez mais recorrentes. Assim, tendo em vista o crescimento de casos dessa natureza, não só no Brasil, esse assunto, pouco presente nos currículos dos cursos de administração, pode vir a ganhar mais espaço e ser utilizado para orientar a revisão de projetos pedagógicos dos cursos de modo a promover o interesse dos estudantes sobre a temática, bem como estimulálos a ter uma visão mais crítica sobre o papel que devem desempenhar no combate aos crimes e ilegalidades nas organizações. Em termos teóricos, este estudo oferece uma visão geral sobre o interesse e a opinião pública sobre os crimes e ilegalidades corporativas, visando à construção de teorias mais robustas sobre o tema. 
As limitações da pesquisa se devem à abordagem quantitativa que, conforme Gil (2002) representa um retrato reducionista da complexidade social, não conseguindo captar o ponto de vista do indivíduo por utilizar grandes amostras, e afastando o pesquisador do dia a dia do objeto. Além do mais, os resultados alcançados com a pesquisa dos estudantes sobre crimes corporativos não poderão ser generalizados a todos os estudantes de graduação em áreas de gestão, uma vez que foram pesquisados apenas estudantes de quatro instituições localizadas na cidade de Uberlândia-MG. Outro limite é o fato de não se ter conseguido a mesma quantidade de amostra para cada um dos perfis pesquisados, o que possibilitaria aumentar o nível de significância do estudo.

Por fim, uma agenda de pesquisa é endereçada: (I) pesquisar se a sociedade em geral compreende o "Crime Corporativo" em sua plenitude, ou seja, investigar se trabalhadores e consumidores consideram determinadas situações como crimes nas organizações ou não; (2) fazer uma pesquisa qualitativa com executivos, consumidores e trabalhadores que foram envolvidos direta ou indiretamente em ações ilegais e/ ou criminosas nas organizações; (3) pesquisar a opinião pública sobre crimes corporativos envolvendo a esfera governamental, como casos de fraudes e corrupção; (4) avaliar a opinião pública a respeito de um tipo específico de crime ou ilegalidade corporativa, buscando analisar com maior profundidade o conhecimento, a percepção de gravidade e opinião sobre o combate dessa situação; (5) aprofundar na investigação se a categoria gênero influencia a opinião e interesse sobre os crimes corporativos; (6) investigar a influência do discurso do "mito do empreendedor de sucesso" na percepção de crimes corporativos; e (7) investigar as possíveis influências culturais, como, por exemplo, a distância de poder entre as organizações e sociedade, na opinião e interesse sobre a temática. 


\section{REFERÊNCIAS}

ADLER, P.S. Corporate scandals: it's time for reflection in business schools. Academy of Management Executive, v. 16, n. 3, p. 148-159, 2002.

AKTOUF, O. Ensino de Administração: Por uma Pedagogia para a Mudança.

Organizações \& Sociedade, v. 13, n. 12, p. 151-159, 2005.

ALCADIPANI, R. Corrupção e as empresas. GV Executivo, v. 13, n. 1, p. 68, 2014.

ALCADIPANI, R; BERTERO, C. O. Guerra Fria e ensino do management no Brasil: o caso da FGV-EAESP. Revista de Administração de Empresas, v. 52, n. 3, p. 284-299, 2012.

ALMOND, P. Understanding the seriousness of corporate crime. Some lessons for the new 'corporate manslaughter' offence. Criminology \& Criminal Justice, v. 9, n. 2, p.145164, 2009.

BARCELLOS, R. M. R.; DELLAGNELO, E. L.; SALIÉS, G. P. Universidade, Sociedade e Formação do Administrador: Uma Reflexão Necessária. Administração: Ensino e Pesquisa, v. 12, n. 4, p. 671-696, 2011.

BAUCUS, M. S.; DWORKIN, T.M. What Is Corporate Crime? It Is Not Illegal Corporate Behavior. Law \& Policy, v. 13, n. 3, p. 231-244, 1991.

BAUCUS, M.S. Pressure, Opportunity and Predisposition: a multivariate Model of Corporate Illegality. Journal of Management, v. 20, n. 4, p. 699-721, 1994.

BENNIS, W. G.; O’Toole, J. How business schools lost their way. Harvard Business Review, v. 83, n. 5, p. 96-104, 2005.

BORGES, J. F.; MEDEIROS, C. R.; CASADO, T. Práticas de gestão e representações sociais do administrador: algum problema? Cadernos EBAPE.BR, v. 9, n. Ed. Especial, art. 5, p. 530-568, 2011.

BORGES, S.R.P.; MEDEIROS, C.R.O. Crimes corporativos no Brasil: uma análise de grandes empresas no Estado de Minas Gerais. Congresso Brasileiro de Estudos Organizacionais, 2, 2014, Uberlândia. Anais... Uberlândia: SBEO 2014.

CARVALHO, L. Empresas com bom resultado são mais corruptas. Revista Exame. Publicado em: 28/09/2010. Disponível em: <http:/ / exame.abril.com.br/gestao/ noticias/empresas-bom-resultado-sao-mais-corruptas-600223 $>$. Acesso em: 28/09/2013.

COLEMAN, J. W. A elite do crime: para entender o crime do colarinho branco. 5.ed. São Paulo: Manole, 2005.

CULLEN, F. T.; BRUCE, G.; CRAIG, W. P. The Seriousness of Crime Revisited: have attitudes toward White-Collar Crime changed? Criminology, v. 20, n, 1, p. 83-102, 1982.

FRANK, J; CULLEN, F.T; TRAVIS, L.F; BORNTRAGER, J.L. Sanctioning corporate crime: How do business executives and the public compare? American Journey of Criminal Justice, v. 13, n.9, p.139-169, 1989.

FERREIRA, D. A.; FERREIRA, L.; FARIA M. D. O Ensino da Ética em Administração: 
Percepções e Opiniões dos Alunos. Administração: Ensino e Pesquisa, v. 12, n. 1, p. 4164, 2011.

FONTENELLE, I. A. A Auto-Gestão de Carreira chega à Escola de Administração: O Humano se tornou Capital? Revista Organizações e Sociedade, v. 14, n. 43, p.71-89, 2007.

FRIEDRICHS, D.O. Trusted criminals: white collar criminal in contemporary society. 4.ed. Belomont: Cengage Learning, 2010.

FULLER, R. C. Morals and the Criminal Law, Journal of Criminal Law and Criminology, v. 32, n. 6, p. 623-630, 1942.

GIL, A. C. Como elaborar projetos de pesquisa. 4.ed. São Paulo: Atlas, 2002.

GIOIA, D. A. Business education's role in the crisis of corporate confidence. Academy of Management Executive, v. 16, n. 3, p. 142-145, 2002.

GHOSHAL, S. Bad Management Theories Are Destroying Good Management Practices. Academy of Management Learning \& Education, v. 4, n. 1, p. 75-91, 2005.

GRABOSKY, P.; BRAITHWAITE, J. Corporate Crime in Australia. Australian Institute of Criminology. Trends \& Issues in crime and criminal justice, n. 5, p. 1-5, 1987.

GREY, C.; KNIGHTS, D.; WILMOTT, H. Is a critical pedagogy of management possible? In: GREY, C.; FRENCH, R. Rethinking management education. Sage: London, 1996.

GREY, C. Reinventing business schools: the contribution of critical management education. Academy of Management Learning and Education, v.3, n.2, p.178-186, 2004. GRIFFIN, R. W.; O'LEARY-KELLY, A. The Dark Side of Organizational Behaviour. San Francisco, CA: Jossey-Bass, 2010.

HANS, V. P; ERMANN, M. D. Responses to corporate versus individual wrongdoing, Law and Human Behaviour, v 13, n. 2, p. 151-66, 1989.

HBR. A Harvard Business Review debates: How to Fix Business Schools. 02/04/ 2009. Disponível: http://metacool.typepad.com/metacool/2009/04/harvard-business-reviewdebate-how-to-fix-business-schools.html Acesso em: 04/04/2015.

LAKATOS, E. M; MARCONI, M. A. Fundamentos de metodologia científica. 6.ed. São Paulo. Atlas, 2007.

MEDEIROS, C.R.O. Inimigos públicos: Crimes Corporativos e Necrocorporações. 2013. 316 f. Tese (Doutorado em Administração), Fundação Getúlio Vargas, São Paulo, 2013.

MEDEIROS, C. R.O.; ALCADIPANI, R. Crimes corporativos contra a vida e necrocorporações. In: ENCONTRO NACIONAL DE PÓS-GRADUAÇÃO EM ADMINISTRAÇÃO, 37, 2013, Rio de Janeiro. Anais.... Rio de Janeiro: ANPAD, 2013a. MILLER, J.L; ROSSI, P.H; SIMPSON, J.E. Felony Punishments: A factorial survey of perceived justice in criminal sentencing, Journal of Criminal Law and Criminology, v. 82, n. 2, p. 396-422, 1991. 
MITROFF, I.I. An Open Letter to the Deans and de Faculties of American Business Schools. Journal of Business Ethics, v. 54, n. 2, p. 185-189, 2004.

MORGAN, G. Images of organization. London: Sage Publications, 1996.

MOTTA, F.C.P. A questão da formação do administrador. Revista de Administração de Empresas, v. 23, n.4, p. 53-55, 1983.

NICOLINI, A. Qual será o futuro das fábricas de administradores? Revista de Administração de Empresas, v. 43, n. 2, p. 44-54, 2003.

OLIVEIRA, C.R.O.; VALADÃO JÚNIOR, M.V.; MIRANDA, R. Culpada ou inocente? Comentários de internautas sobre crimes corporativos. Revista de Administração de Empresas, v.53, n.6, p. 617-628, 2013.

PATON, S.; CHIA, R.; BURT, G. Relevance ou 'relevate'? How university business schools can add value through reflexively learning from strategic partinerships with business. Management Learning, v. 45, n. 3, p. 267-288, 2014.

PAYNE, B. K. White-collar Crime. The Essentials. Georgia: Sage Publications, 2012. REBOVICH, D. J.; KANE, J. L. Eye for an Eye in the Electronic Age: Public Attitude Toward White Collar Crime and Punishment. Journal of Economic Crime Management, v. 1, n.2, p. 1-19,2002.

ROSENMERKEL, S. P. Wrongfulness and harmfulness as components of seriousness of White-Collar offenses, Journal of Contemporary Criminal Justice, v. 17, n.4, p. 308-27, 2001.

RUBIN, R.S.; DIERDOFF, E.C. How Relevant Is the MBA? Assessing the Alignment of Required Curricula and Required Managerial Competencies. Academy of Management Learning and Education, v.8, n.2, p.208-224, 2009.

SANTOS, R.A; GUEVARA, A.J.H.; AMORIM, M.C.S. Corrupção nas organizações privadas: análise da percepção moral segundo gênero, idade e grau de instrução, Revista de Administração de Empresas da USP, v.48, n.1, p.53-66, 2013.

SANTOS, J. P.; SILVA, R. C. M. A Percepção dos Estudantes sobre o Ensino da Responsabilidade Social Corporativa na Graduação em Administração. Administração: Ensino e Pesquisa, v. 14, n. 2, p. 377-401, 2013.

SCHRAGER, L.S.; SHORT JR., J.F. Toward a Sociology of Organizational Crime. Social problems, v. 25 , n. 4, p. 407-419, 1978. SIMPSON, S. S. Corporate crime, law and social control. New York: Cambridge studies criminology, 2002.

SILVA, R. C. M.; CHAUVEL, M. A. Responsabilidade social no ensino em administração: um estudo exploratório sobre a visão dos estudantes de graduação. Revista de Administração Pública, v. 45, n. 5, 2011.

STYLIANOU, S. Measuring Crime Seriousness Perceptions: what have we learned and what else do we want to know? Journal of Criminal Justice, v. 31, n. 1, p. 37-56, 2003. 
SUTHERLAND, E.H. White-Collar Criminality. American Sociological Review, v. 5, n. 1, p. 1-12, 1940.

SZWAJKOWSKI, E. Organizational illegality: Theoretical integration and Illustrative Application. The Academy of Management Review, v. 10, n. 3, p. 558-567, 1985.

TEIXEIRA, M. P. R.; SILVA I. C.; MAFRA, F. L. N. Reflexões Sobre a Formação do Administrador: Uma Abordagem a partir da Inserção das Questões Sociais nos Conteúdos Disciplinares. Revista Symposium, 2011.

THIRY-CHERQUES, H.R. O conformismo impaciente: uma interpretação do quadro de referência ética dos jovens executivos nas organizações brasileiras. Revista de Administração Pública, v. 38, n. 4, p. 613-642, 2004.

TURNER, T. Combating corporate crime. Brigham Young University Prelaw Review, v. 18, n.1, p. 29-38, 2005.

TVERSKY, A.; KAHNEMAN, D. Judgment under Uncertainty: heuristics and biases, Science, New Series, v.185, n. 4157, p. 1124-1131, 1974.

UNNEVER, J.D.; BENSON, M. L.; CULLEN, F.T. Public Support for Getting Tough on Corporate Crime. Racial and Political Divides. Journal of Research in Crime and Delinquency, v. 45, n. 2, p. 163-190, 2008.

VERGARA, S. C. Projetos e relatórios de pesquisa em Administração. 5.ed. São Paulo: Atlas, 2004.

VERGARA S. C.; BRANCO, P. D. Empresa Humanizada: A organização necessária e possível. Revista de Administração de Empresas, v. 41, n. 2, p. 20-30, 2001.

WARR, M. What is the perceived seriousness of crimes? Criminology, v. 27, n.4, p. 795-821, 1989.

WELSH, M. A.; DEHLER, G. E. Whither the MBA? Or the Withering of MBAs? Management Learning, v. 38, n.4, p. 405-426, 2007.

WOOD JR., T.; CALDAS, M. P. Empresas brasileiras e o desafio da competitividade. Revista de Administração de Empresas, v. 47, n. 3, p. 66-78, 2007. 


\section{SABRINA RAFAELA PEREIRA BORGES` sabrinarpb@yahoo.com.br} Mestre em Ciências Contábeis pela UFU

Instituição de vinculação: Universidade Federal de Uberlândia

Uberlândia/MG - Brasil

Áreas de interesse em pesquisa: Estudos Organizacionais, Finanças Comportamentais e Instrumentos Financeiros.

*Av. João Naves de Ávila, 2121, Sala 233 Bloco $1 F \quad$ Santa Monica Uberlândia/MG 38408-100

\section{CINTIA RODRIGUES DE OLIVEIRA MEDEIROS cintia@ufu.br}

Doutora em Administração pela FGV/EAESP

Instituição de vinculação: Universidade Federal de Uberlândia Uberlândia/MG - Brasil

Áreas de interesse em pesquisa: Estudos Organizacionais, Cultura, Poder e Gênero.

\section{NADIA GIARETTA BIASE nadiabiase@gmail.com}

Doutora em Estatística pela UFLA

Instituição de vinculação: Universidade Federal de Uberlândia Uberlândia/MG - Brasil

Áreas de interesse em pesquisa: Comparações Múltiplas de Parâmetros Binomiais, Método de Monte Carlo e Regressão.

\section{VALDIR MACHADO VALADÃO JÚNIOR valdirjr@ufu.br}

Doutor em Engenharia de Produção pela UFSC

Instituição de vinculação: Universidade Federal de Uberlândia

Uberlândia/MG - Brasil

Áreas de interesse em pesquisa: Ensino em Administração, Cultura, Sustentabilidade e Terceiro Setor.

A presente pesquisa contou com o apoio financeiro do CNPq. 